\title{
Minimizing the Weight of Cantilever Beam via Metaheuristic Methods by Using Different Population-Iteration Combinations
}

\author{
MELDA YÜCEL \\ Department of Civil Engineering \\ Istanbul University-Cerrahpaşa \\ 34320 Avc1lar, Faculty of Engineering, Istanbul, Turkey \\ TURKEY \\ melda.yucel@yahoo.com.tr \\ GEBRAIIL BEKDAŞ \\ Department of Civil Engineering \\ Istanbul University-Cerrahpaşa \\ 34320 Avc1lar, Faculty of Engineering, Istanbul, Turkey \\ TURKEY \\ bekdas@istanbul.edu.tr https://avesis.istanbulc.edu.tr/bekdas \\ SİNAN MELİH NİGDELI \\ Department of Civil Engineering \\ Istanbul University-Cerrahpaşa \\ 34320 Avc1lar, Faculty of Engineering, Istanbul, Turkey \\ TURKEY \\ melihnig@istanbul.edu.tr https://avesis.istanbulc.edu.tr/melihnig/
}

\begin{abstract}
Since a long time, metaheuristic algorithms are benefited to detect the best results for any optimization problem. Furthermore, these methods are used to prevent of time, effort and cost losses, while they are performing the optimization process. Hence, in this study, a cantilever beam model, which is one of the structural optimization problem from civil engineering area, was handled with the aim of minimization of the total weight by find the optimum section values consisting of hollow section depths and widths. For this reason, three different methods including the algorithms that artificial bee colony (ABC), bat (BA), and a modified bat (MBA) combining of BA with Lévy flight, were operated. Additionally, several applications previously carried out for this model, were presented in order to compare of optimization results (minimum objective function with optimum design variable values), and success of proposed algorithm was showed with statistical results and optimization parameter values.
\end{abstract}

Key-Words: Metaheuristic methods, Artificial Bee Colony (ABC), Bat Algorithm (BA), Modified Bat Algorithm (MBA), Levy flight, Weight optimization, Cantilever beam, Comparison.

Received: September 8, 2019. Revised: March 3, 2020. Accepted: April 9, 2020. Published: April 30, 2020.

\section{Introduction}

One of the most important topics of structural engineering is to realize of the most convenient, namely optimum design of structural members that rules of economically, aesthetics, sustainable and safety can be ensured all together in ways that not put life of alives in danger. As to actualizing of this state is not so easy. Because, many different combinations can arise for any design, depending on environment and design conditions, and to determine the best one of them usually depends on the factors such as experience, knowledge, foresight of engineer, which is responsible about creating of the design. On the other hand, every time, able to say is not possible that design, which is achieved intended to the given circumstances, is the best one. Because, it is needed that calculations, which are step by step, and can take the design to the best state, to find the optimum one. However, this process is very time-consuming and therefore, it is seen as a case causing to loss of cost, besides a necessity of hard effort, too.

From past to present, various optimization methods were used to prevent of such these 
negations in the process of reaching to the best result for any design or problem. In nowadays, metaheuristic algorithms, which are nature-based and considered as advanced optimization methods, are employed. It is seen that these methods provide of the improvement iteratively by evaluate of many solutions one by one, and thus, they designed with the aim of reaching to the best result, when they are compared with the classical hand calculations and computer programs.

Accordingly, many optimization applications were performed by using of metaheuristic algorithms in various engineering areas. One of these is a study that Marinelli et al. [1] applied a hybrid approach for an optimization problem related to determination of flight gates by combining of two different algorithms: bee colony optimization (BCO) and biogeography-based optimization (BBO). Shilaja and Ravi [2] used flower pollination (FPA) and Krill-Herd algorithm to determine optimum size and positions of systems at stake, with the purpose of determining of the most suitable generators besides amount of optimum power flowing in heat production unites. Also, a study was performed in order to optimize of emissions containing hydrocarbon (HC), carbon monoxide (CO), nitrogen oxide (NOx) and particulate matter (PM) together with fuel consumption for motor of hybrid electricity vehicle by using of grey wolf optimization (GWO) method [3].

Moreover, civil engineering is an area, in where optimization studies are executed frequently, and some from applications, which are taken part in literature that metaheuristic methods were used, is as: in water engineering, Ehteram et al. [4] applied an optimization for operation process of two different reservoir and dam structures by utilizing from three different metaheuristics including particle swarm optimization (PSO), genetic algorithm (GA) with shark algorithm. Another one, that Akbarifard and Radmanesh [5] used three metaheuristics containing symbiotic organisms search (SOS) algorithm with PSO and imperialist competitive algorithm (ICA) by means of estimating the length of waves occurring in two different time ranges as daily and hourly, for Chabahar region of Iran. In geotechnical engineering, Qi and Tang [6] tried to predict of slope stability with various hybrid methods combining of metaheuristics and machine learning algorithms. In this study, firefly algorithm (FA) was used for adjusting the parameters of machine learning techniques. Also, the study, which was realized by Sonmez et al. [7], that they performed upon two different cases by using artificial bee colony ( $\mathrm{ABC}$ ) to determine of the transportation energy demand of Turkey that the models, which were generated based on gross domestic product, population and total annual vehicle-km data, can be shown as one of the optimization study, which was performed in transportation branch of civil engineering.

Furthermore, in structural engineering area, there are so many optimization studies applied for detecting of optimal design parameters through specific purposes such as minimum cost, weight, thickness or maximum profit, safety etc. For example, Degertekin and Hayalioglu [8] realized an application that in providing of weight minimization for four different truss structures, by using of teaching-learning based optimization (TLBO), which is one of the population-base metaheuristic algorithms. At the same time, effectiveness of algorithm was observed by compared optimum results obtained for respective application structures previously via various metaheuristic methods, with TLBO. Tapao and Cheerarot [9] used ABC algorithm to provide the minimization of total cost containing of concrete, reinforcement bar, and labor costs of reinforced concrete frames under loadcombinations. Also, design variables are crosssection of structure with numbers and diameters of steel bars that they were used for formulization of optimization problem. Additionally, as in the study performed by Yucel et al. [10], an I-section beam model was optimized with FPA by means of minimizing the cost and find of the optimum design variables including beam flange width and thickness, beam height, web thickness.

Besides of these, the other studies are related to the optimum design of steel beam-column shape with crow search algorithm (CSA) [11] and cost minimization of prestressed-beam with differential evolution (DE) [12]; generation of the optimum design model for reinforced concrete cantilever retaining wall by using ant colony optimization (ACO) [13] and cuckoo search (CS), FA and two different PSO algorithms [14] optimization of structure weight for truss and frame via harmony search (HS) [15], FPA [16] and school-based optimization (SBO) [17]; besides, sizing and layout/shape optimization for these structures by using TLBO [18] and jaya algorithm (JA) [19].

In this study, two different population-based metaheuristic methods were benefited to carry out the design of a cantilever beam model with minimum weight. In this direction, it was ensured that the best section values were determined by the result of optimization application, which was realized by using artificial bee colony (ABC), bat algorithm (BA), and modified bat algorithm (MBA) 
generated with Lévy flight. Furthermore, the case can be determined that beam design with minimum weight, and optimum section values of this design can arise in what iteration and population number, thanks to various combinations obtained by usage of multiple iteration and population numbers.

\section{Metaheuristic Methods}

\subsection{Artificial Bee Colony (ABC) Algorithm} Artificial bee colony (ABC), which was developed by Derviş Karaboğa in 2005, is one of the population-based metaheuristic algorithms. This method was designed by depending foraging behaviors of bee colonies, and half of colony is consisted of honey bees; and onlooker bees are generated the other half [20].

The purpose of bees is to increase amount representing the quality of nectar in hive, about the behavior of food-searching. On the other side, in algorithm structure, the positions of food source express the possible candidate solutions. For this respect, bees detect the best food sources by exploring the different locations, and so maximize of the nectar amount. Some acceptances and assumptions were made for applying of this process with the aim of optimization about various problems [21]:

1. Assumed that employee and onlooker bee numbers are equal in population consisting of colony.

2. Assumed that employee (and onlooker) bee number is equal with the number of food sources. Therefore, in population, each bee can go to only one food source (candidate solution) and completely consumes this.

3. Accepted that employee bees transform to scout bees to find the new ones for nectarfinished food sources.

Optimization process, which is formed in the direction of these rules arranged based on natural process inspiring by $\mathrm{ABC}$ algorithm, is performed in three different stages: employee bee, onlooker bee and scout bee.

In employee bee stage, any food source $(\mathrm{k})$ and a design variable $(\mathrm{p})$ belonging problem are selected randomly. Following, new food source positions (X (p,new) ) are determined with Eq. (1) by using the possibility value $(\phi(i, j))$, which is calculated with Eq. (2) and ranges between [-1,1]. In consequence of realized of this process, source positions are updated by changing of all foods with old ones, which are better than initial state in terms of nectar amount [21].

$X_{p, \text { new }}=X_{p, j}+\phi_{\mathrm{i}, \mathrm{j}}\left(X_{p, j}-X_{p, k}\right)$

$\phi_{\mathrm{i}, \mathrm{j}}=-1+2 \operatorname{rand}()$

Bees are informed by employee bees about nectar inside of sources in onlooker stage, which is second stage. Food quality/rate/possibility $\left(\mathrm{P}_{\mathrm{j}}\right)$ are calculated by considered of all nectar amounts, then evaluated by onlooker bees (Eq. (4)). This operation is related to selection of the ones that they have rich nectar amount from renewed food sources previously, and in this way, sources can be improved consistently. In here, expressed that Nectar $_{j}$ is nectar amount of $j^{\text {th }}$ food source; $f n$ is source number, and process is realized as stated in Eq. (3) [22].

$$
\begin{aligned}
& X_{p, \text { new }}=\left\{\text { rand }<\mathrm{P}_{\mathrm{j}}, X_{p, j}+\phi_{\mathrm{i}, \mathrm{j}}\left(X_{p, j}-X_{p, k}\right)\right. \\
& \mathrm{P}_{\mathrm{j}}=\frac{\text { Nectar }_{\mathrm{j}}}{\sum_{\mathrm{j}=1}^{f n} \text { Nectar }_{\mathrm{j}}}
\end{aligned}
$$

Finally, new sources are founded for nectarfinished sources. This process is scout bee stage. In this stage, improvement parameter 『(ip)_j) of each source is controlled with a constant source improving limit (SIL) assigned in beginning (Eq. (5)), and new source is determined for each that provided of condition $[22,23]$.

$X_{i, \text { new }}=\left\{\mathrm{ip}_{\mathrm{J}}>S I L, X_{i, \min }+\operatorname{rand}()\left(X_{i, \max }-X_{i, \min }\right)(5)\right.$

\subsection{Bat Algorithm (BA)}

The bat algorithm is a population-based metaheuristic algorithm as in $\mathrm{ABC}$, developed in the year of 2010 by Xin-She Yang. The main nature source that this algorithm takes inspire, is the echolocation behaviour of bats. This behaviour provides benefits for some activities required for survival of bats in nature, such as detection of preys' location, protection from obstacles, locating the coves in which they live at night. On the other hand, as with all metaheuristics, it is necessary to correctly adjust of some natural properties of bats and make some assumptions in order to that BA algorithm can be used in optimization applications and to be effective in realizing the process. These are [24]:

i. Bats use the sound echo to perceive the distance. 
ii. Bats use a sound that has constant $f$ frequency, variable $\lambda$ wavelength and $A_{0}$ loudness while questing their preys and moves randomly in any $X_{i}$ position via $V_{i}$ velocity. They adjust the wavelength/frequency of sound automatically; and vibration emission rate $(r \in[0,1])$ according to closeness of prey.

iii. Assumed that the loudness $\left(A_{j}\right)$ changes between an extremely big initial value $\left(A_{0}\right)$ and a minimum value $\left(A_{\text {min }}\right)$. Accordingly, bat starts to look for prey with a very loud sound $\left(A_{0}=\right.$ 1 ); it can be said that it abandons to give out sound temporarily also when it found the prey of it $\left(A_{\min }=0\right)$.

Accordingly, each $\mathrm{j}^{\text {th }}$ bat' $\mathrm{s}$ loudness $\left(A_{j}\right)$ and vibration transmission ratio $\left(r_{j}\right)$ are different and the other features such as current frequency $\left(f_{j}\right)$ and velocity $\left(V_{i, j}\right)$ must be considered while new values of velocity $\left(V_{i, n e w}\right)$ and location $\left(X_{i, n e w}\right)$ of bats is determining.

Here, it is expressed with that $X_{i, g_{\text {best }}}$ is the best candidate in terms of objective function in the whole bat population; $X_{i, j}$ is $\mathrm{j}^{\text {th }}$ bat location (candidate solution) for $\mathrm{i}^{\text {th }}$ design variable, besides $f_{\max }$ and $f_{\text {min }}$ indicate the lower and upper values of frequency belong to bats, respectively. The optimization process in question is carried out with BA, through Eqs. (6-8) seen as below:

$$
\begin{aligned}
& f_{\mathrm{j}}=f_{\min }+\left(f_{\max }-f_{\min }\right) \operatorname{rand}() \\
& V_{i, \text { new }}=V_{i, j}+\left(X_{i, j}-X_{i, g_{\text {best }}}\right) f_{j} \\
& X_{i, \text { new }}=X_{i, j}+V_{i, \text { new }}
\end{aligned}
$$

In the second stage, an update for the determined new locations is at stake. This operation states the process called as local search by using a random walk and is made with Eq. (9). $A_{\text {mean }}$ indicates the mean of loudness of all bats and $\beta$ is a constant (range in $[-1,1]$ ) related with loudness transmission [25]. In addition, random walk can be applied with a random distribution as Lévy flight function [16]. Also, MBA (modified bat algorithm) is created to use in optimization process by combined of BA with Lévy (Eq. (10)).

$$
X_{i, \text { new }}=\left\{\text { rand }>r_{j}, X_{i, g_{\text {best }}}+\beta A_{\text {mean }}\right.
$$

$$
\text { Lévy }=\left(\frac{1}{\sqrt{2 \pi}}\right)(\operatorname{rand}())^{-1.5} e^{\left(-\frac{1}{2 \operatorname{rand}()}\right)}
$$

Since change of the positions of bats by updated, their distance to prey or food also changes. From this respect, loudness $\left(A_{j, n e w}\right)$ and vibration transmission rate $\left(r_{j, \text { new }}\right)$ should be recalculated throughout iterations [26]. These parameters are determined by Eq. (11) and (12) respectively.

$$
\begin{aligned}
& A_{j, \text { new }}=\alpha A_{j} \\
& r_{j, \text { new }}=r_{j}^{0}\left(1-e^{-\gamma t}\right)
\end{aligned}
$$

From expressions in these formulas, that $\alpha$ is a constant coefficient effective for transferring of sound loudness; $r_{j}^{0}$ is initial voice vibration emission rate of bats; $\gamma$ is a constant coefficient that defines of sound vibration emission rate, and $t$ is the current iteration number [27].

\section{Weight Minimization of Cantilever Beam Model}

In the current optimization application, the weight of a five-piece and fixed-connected cantilever beam that vertical P load applied from its end point, and consisted from divisions, which have hollowed square sections, was minimized. Design belong to model was created by Fleury and Braibant [28] and it can be seen in Figure 1.

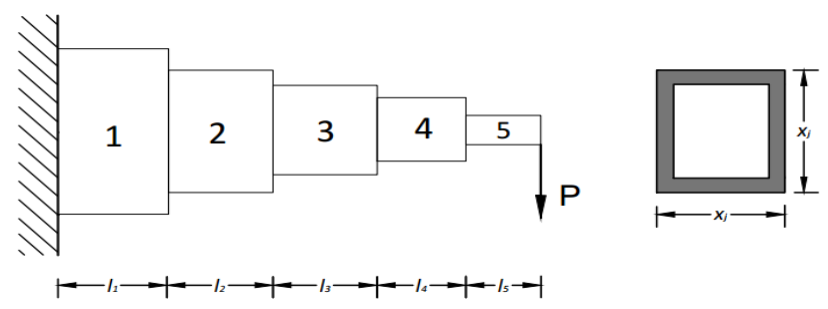

Fig. 1. Cantilever beam model and hollow section sizes [28].

As seen in Figure 1, values of $\boldsymbol{l}_{\boldsymbol{j}}(j=1,2, \ldots, 5)$ is length of each beam dividing and $\boldsymbol{x}_{\boldsymbol{j}}(j=1,2, \ldots, 5)$, which are design variables, express the sizes of hollow section, also thickness $(\boldsymbol{t})$ of sections are determined constant as $2 / 3$. The objective function $\left(\mathrm{f}\left(\mathrm{x}_{\mathrm{j}}\right)\right)$ optimization, is taken part in Eq. (13).

$\operatorname{Min} f\left(x_{j}\right)=0.0624\left(x_{1}+x_{2}+x_{3}+x_{4}+x_{5}\right)$ 
Upper and lower bounds (ranges) belong to width and depth sizes of hollow section, which are design variables, are as below:

$0.001 \leq x_{j} \leq 100$

On the other hand, some limitations or constraints are considered during design. $\mathrm{g}_{1}$ constraint, which is controlled as design limitation in problem, is expressed in below Eq. (15):

$\mathrm{g}_{1}=\frac{61}{x_{1}^{3}}+\frac{37}{x_{2}^{3}}+\frac{19}{x_{3}^{3}}+\frac{7}{x_{4}^{3}}+\frac{1}{x_{5}^{3}}-1 \leq 0$

\section{Optimization Process via BA and ABC Algorithms}

In this application, two different metaheuristic methods were applied in order to determine of the best solution and design variables with the minimum weight value belonging to it by scanning from a large-scale searching area. For this reason, firstly, optimization results were obtained via using of $\mathrm{BA}$ and $\mathrm{ABC}$ through taken of iteration number ranging in 1 and 2000, and population number ranging between 5 and 40. In this regard, it is possible that the best solution is detected among all iteration-population combinations, by comparing with optimum results obtained previously in literature studies, which were applied with MMA [29], GCA [30], CS [31] etc. respectively.

Additionally, properties of the current optimization process are summarized in Table 1.
Table 1. The optimization application properties

\begin{tabular}{cc}
\hline Optimization members & Information \\
\hline & $\mathrm{ABC}$ \\
Method & $\mathrm{BA}$ \\
& $\mathrm{MBA}$ \\
\hline Population number & $5-40$ \\
\hline Iteration number & $1-2000$ \\
\hline
\end{tabular}

\section{Result and Conclusion}

Optimum values for minimization of the cantilever beam model by using different metaheuristic algorithms are expressed by means of searched of literature studies and given in Table 2. Also, iteration with population numbers used for determining of these values, can be seen in this table.

As can be seen from the results that the best application as a metaheuristic method is search and rescue optimization (SAR) in terms of minimum weight with smaller population numbers than the other ones. However, the optimum results together with minimum value of objective function are shown in Table 3, that were found by existing methods consist of $\mathrm{ABC}, \mathrm{BA}$ and MBA.

In addition to this, in Figure 2, 3 and 4, graphics that shown of the minimum weights, which were found according to each iteration and population number combinations, are represented for $\mathrm{ABC}, \mathrm{BA}$ and MBA respectively.

Table 2. The optimum design variable and objective function values with optimization properties from literature works

\begin{tabular}{ccccccccc}
\hline Methods & $\begin{array}{c}\text { Total } \\
\text { Analysis } \\
\text { Number }\end{array}$ & $\begin{array}{c}\text { Population } \\
\text { Number }\end{array}$ & $\boldsymbol{x}_{\mathbf{1}}$ & $\boldsymbol{x}_{\mathbf{2}}$ & $\boldsymbol{x}_{\mathbf{3}}$ & $\boldsymbol{x}_{\mathbf{4}}$ & $\boldsymbol{x}_{\mathbf{5}}$ & $\boldsymbol{f}\left(\boldsymbol{x}_{\boldsymbol{j}}\right)$ \\
\hline MMA [29] & 3 & - & 6.0160 & 5.3090 & 4.4940 & 3.5020 & 2.1530 & 1.3400 \\
\hline MAM [32] & 4 & - & 6.0200 & 5.5300 & 4.7500 & 3.1400 & 2.0300 & 1.3400 \\
\hline GCA $\Delta 1^{\text {st }[30]}$ & 2 & - & 6.0100 & 5.3040 & 4.4900 & 3.4980 & 2.1500 & 1.3400 \\
\hline GCA $\Delta 2^{\text {nd }[30]}$ & 1 & - & 6.0100 & 5.3040 & 4.4900 & 3.4980 & 2.1500 & 1.3400 \\
\hline MAM 2 [33] & 5 & - & 6.0150 & 5.3090 & 4.4930 & 3.5020 & 2.1520 & 1.3390 \\
\hline CS [31] & 250000 & 50 & 6.0089 & 5.3049 & 4.5023 & 3.5077 & 2.1504 & 1.33999 \\
\hline MFA [34] & 15000 & 25 & 6.01422 & 5.31220 & 4.48929 & 3.50375 & 2.15422 & 1.339957 \\
\hline SAR [35] & 10000 & 10 & 6.016081 & 5.309224 & 4.494135 & 3.501578 & 2.152641 & 1.3399563
\end{tabular}

MMA: Methods of moving asymptotes, MAM: Multipoint approximation method, GCA: Generalized convex approximation, $\Delta \mathbf{1}^{\text {st: }}$ First derivative, $\mathbf{\Delta 2}^{\text {nd }}$ : Second derivative, CS: Cuckoo search, MFA: Modified firefly algorithm, SAR: Search and rescue optimization algorithm 
Table 3. Applied optimization results for the cantilever beam problem

\begin{tabular}{ccccccccccc}
\hline Algorithm & $\begin{array}{c}\text { Total } \\
\text { Analysis } \\
\text { Number }\end{array}$ & $\begin{array}{c}\text { Population } \\
\text { Number }\end{array}$ & $\boldsymbol{x}_{\mathbf{1}}$ & $\boldsymbol{x}_{\mathbf{2}}$ & $\boldsymbol{x}_{\mathbf{3}}$ & $\boldsymbol{x}_{\mathbf{4}}$ & $\boldsymbol{x}_{\mathbf{5}}$ & $\begin{array}{c}\text { Min } \\
\boldsymbol{f}\left(\boldsymbol{x}_{\boldsymbol{j}}\right)\end{array}$ & $\begin{array}{c}\text { Mean } \\
\boldsymbol{f}\left(\boldsymbol{x}_{\boldsymbol{j}}\right)\end{array}$ & $\begin{array}{c}\text { Std. } \\
\boldsymbol{d e v i a t i o n} \\
\boldsymbol{f}\left(\boldsymbol{x}_{\boldsymbol{j}}\right)\end{array}$ \\
\hline ABC & 70044 & 39 & 6.047291 & 5.283496 & 4.537044 & 3.445138 & 2.165200 & 1.3402377 & 1.3621166 & 0.0141656 \\
\hline BA & 37950 & 25 & 6.008611 & 5.326014 & 4.489836 & 3.495493 & 2.153895 & 1.3399682 & 1.4874703 & 0.4320868 \\
\hline MBA & 22440 & 33 & 6.017332 & 5.310704 & 4.495169 & 3.497804 & 2.152660 & 1.3399569 & 1.5069001 & 0.6903155 \\
\hline
\end{tabular}

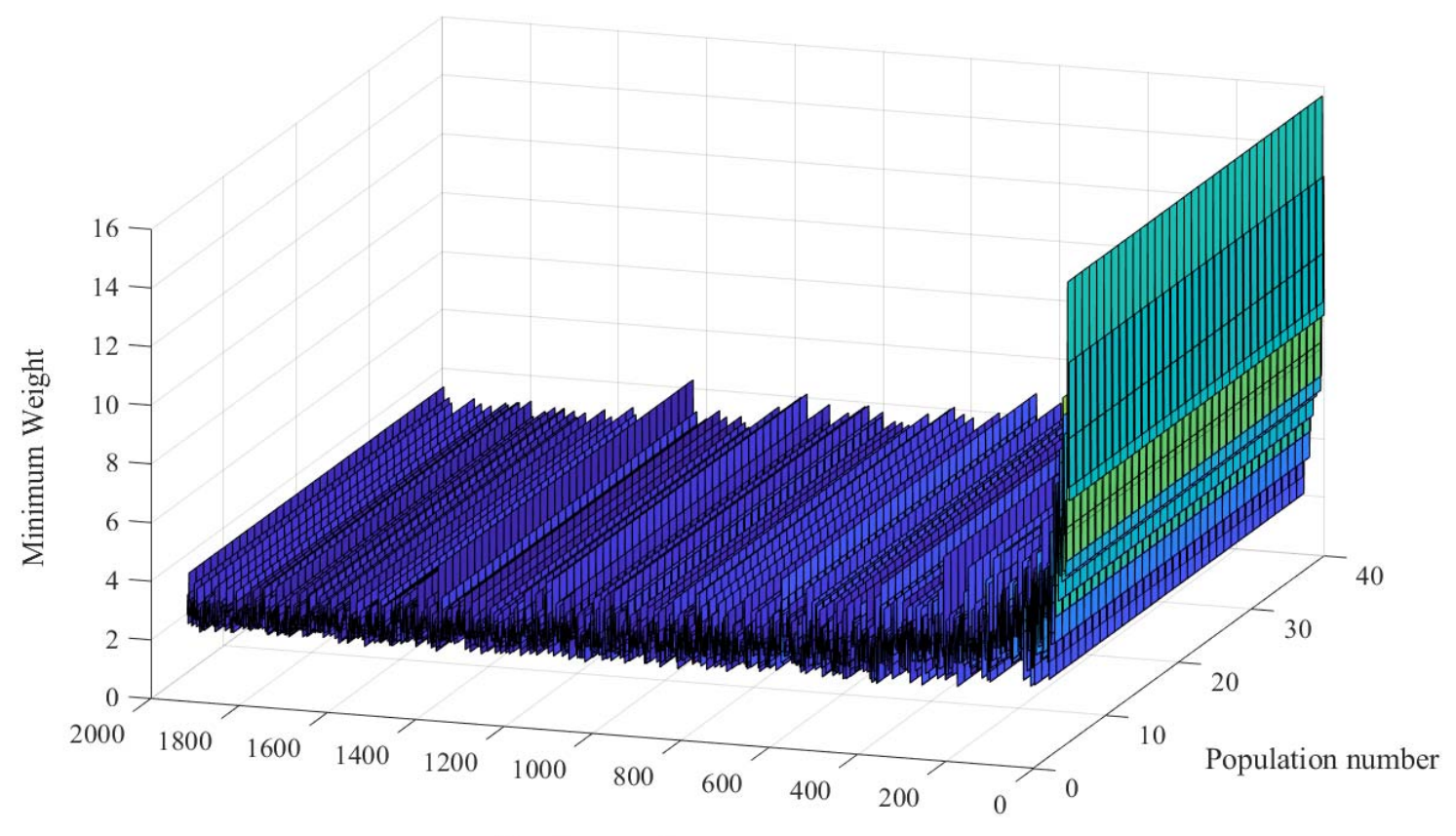

Iteration number

Fig. 2: Minimum weights found according to $\mathrm{ABC}$ for different iteration-population combinations

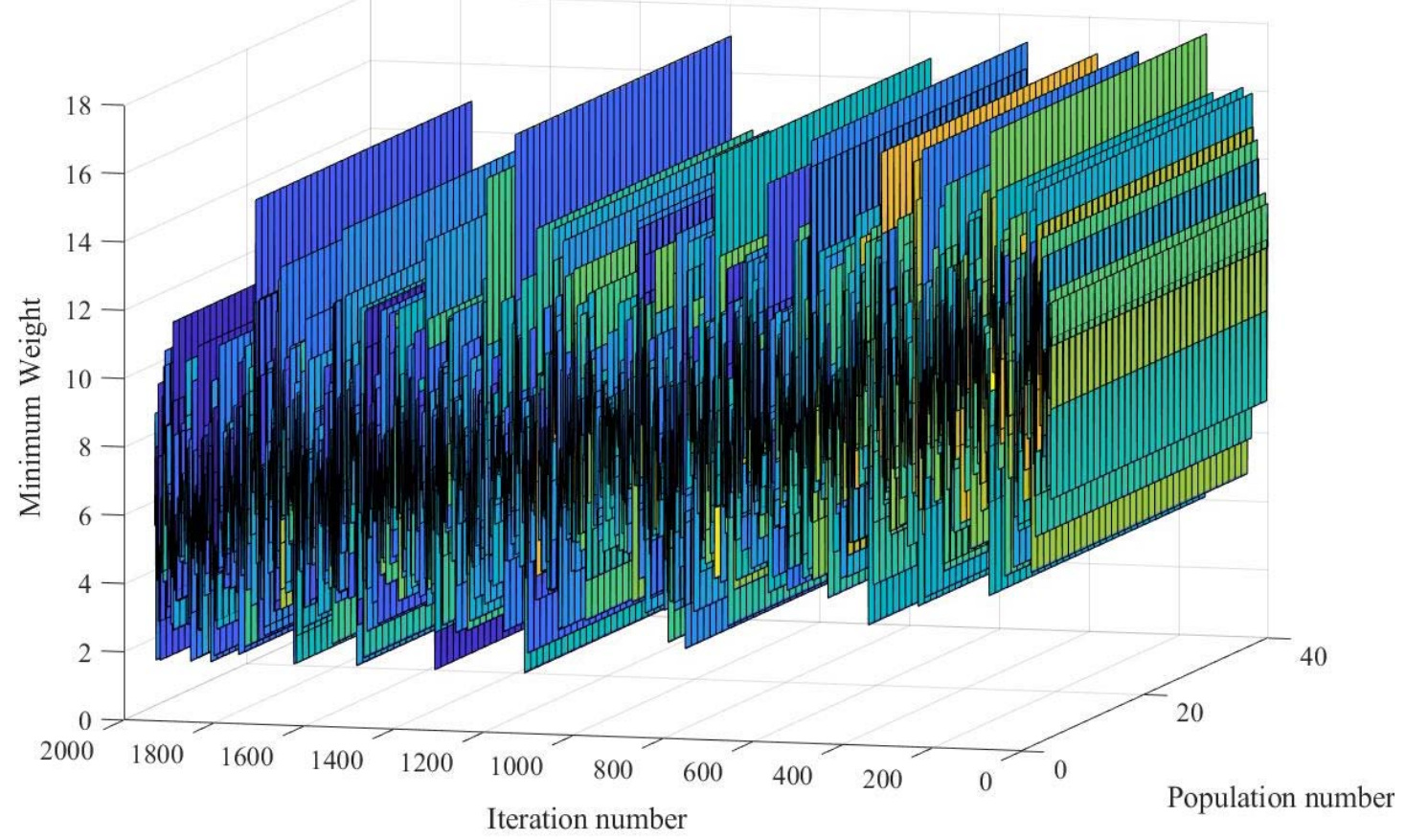

Fig. 3: Minimum weights found according to BA for different iteration-population combinations 


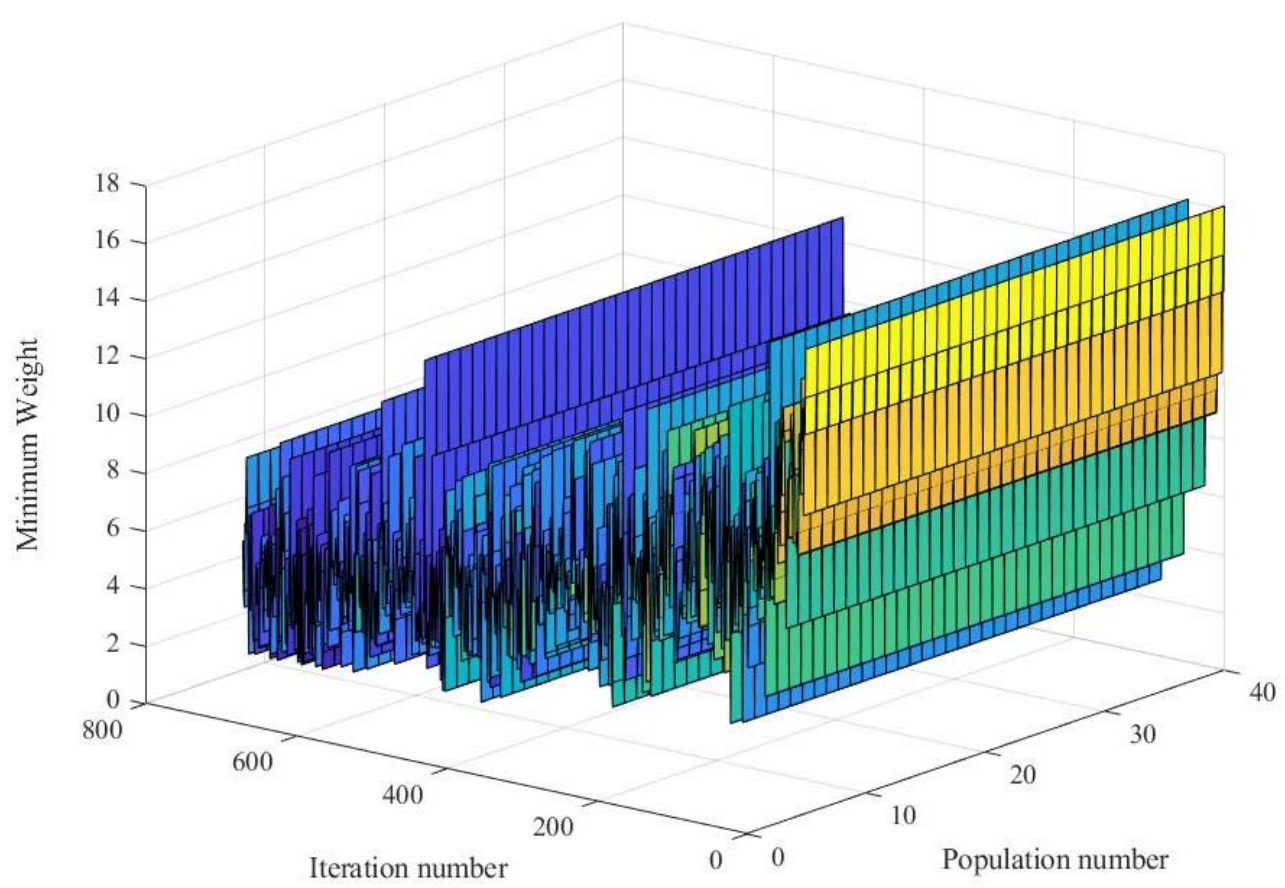

Fig. 4: Minimum weights found according to MBA for different iteration-population combinations

As can be seen that from Table 2 and 3, the best, namely minimum objective function value was ensured as 1.3399563 with SAR method [35]. On the other side, applied in this study, BA and especially MBA can be considered as very effective and convenient method to reach to this value, but $\mathrm{ABC}$ is not so. Reason of this is that $\mathrm{ABC}$ cannot approach completely to the minimum weight value in any iteration-population combination, in despite of convergence to the best solution by gradually with decreasing the error. Consequently, MBA has ability to determine the minimum weight (1.3399569) for cantilever beam model by usage of 33 population number, while reaching the optimum solution ensuring of the best objective function.

\section{References:}

[1] Marinelli, M., Palmisano, G., Dell'orco, M., Ottomanelli, M., 2015, Fusion of two metaheuristic approaches to solve the flight gate assignment problem, Transportation Research Procedia, 10, 920-930.

[2] Shilaja, C., Ravi, K., 2016, Optimal power flow, sizing and location of thermal generating units using metaheuristic soft computing algorithms, Procedia Computer Science, 92, 119-127.

[3] Gujarathi, P.K., Shah, V.A., Lokhande, M.M., 2018, Grey wolf algorithm for multidimensional engine optimization of converted plug-in hybrid electric vehicle, Transportation Research Part D: Transport and Environment, 63, 632-648.

[4] Ehteram, M., Karami, H., Mousavi, S. F., ElShafie, A., Amini, Z., 2017, Optimizing dam and reservoirs operation based model utilizing shark algorithm approach, Knowledge-Based Systems, 122, 26-38.

[5] Akbarifard, S., Radmanesh, F., 2018, Predicting sea wave height using symbiotic organisms search (SOS) algorithm, Ocean Engineering, 167, 348-356.

[6] Qi, C., Tang, X., 2018, Slope stability prediction using integrated metaheuristic and machine learning approaches: a comparative study, Computers \& Industrial Engineering, 118, 112-122.

[7] Sonmez, M., Akgüngör, A.P., Bektaş, S., 2017, Estimating transportation energy demand in turkey using the artificial bee colony algorithm, Energy, 122, 301-310.

[8] Degertekin, S.O., Hayalioglu, M.S., 2013, Sizing truss structures using teaching-learningbased optimization, Computers and Structures, 119, 177-188.

[9] Tapao, A., Cheerarot, R., 2017, Optimal parameters and performance of artificial bee colony algorithm for minimum cost design of reinforced concrete frames, Engineering Structures, 151, 802-820.

[10] Yucel, M., Nigdeli, S.M., Bekdaş, G. (2020). 'Artificial Neural Networks (ANNs) and 
Solution of Civil Engineering Problems: ANNs and Prediction Applications' in Gebrail Bekdaş, Sinan Melih Nigdeli, Melda Yucel (eds.) Artificial Intelligence and Machine Learning Applications in Civil, Mechanical, and Industrial Engineering. IGI Global, pp. 1337.

[11] Ozbasaran, H., 2018, Optimal design of isection beam-columns with stress, non-linear deflection and stability constraints, Engineering Structures, 171, 385-394.

[12] Quaranta, G., Fiore, A., Marano, G.C., 2014, Optimum design of prestressed concrete beams using constrained differential evolution algorithm, Structural and Multidisciplinary Optimization, 49(3), 441-453.

[13] Ghazavi, M., Bonab, S.B., 2011, Optimization of reinforced concrete retaining walls using ant colony method, ISGSR Geotechnical Safety and Risk, 2-3 June 2011 Munich-Germany, 297-306.

[14] Gandomi, A.H., Kashani, A.R., Roke, D.A., Mousavi, M., 2015, Optimization of retaining wall design using recent swarm intelligence techniques, Engineering Structures, 103, 72-84.

[15] Maheri, M.R., Narimani, M.M., 2014, An enhanced harmony search algorithm for optimum design of side sway steel frames, Computers \& Structures, 136, 78-89.

[16] Bekdaş, G., Nigdeli, S.M., Yang, X.S., 2015, Sizing optimization of truss structures using flower pollination algorithm, Applied Soft Computing, 37, 322-331.

[17] Farshchin, M., Maniat, M., Camp, C.V., Pezeshk, S., 2018, School based optimization algorithm for design of steel frames, Engineering Structures, 171, 326-335.

[18] Dede, T., Ayvaz, Y., 2015, Combined size and shape optimization of structures with a new meta-heuristic algorithm, Applied Soft Computing, 28, 250-258.

[19] Degertekin, S.O., Lamberti, L., Ugur, I.B., 2018, Sizing, layout and topology design optimization of truss structures using the Jaya algorithm, Applied Soft Computing, 70, 903928.

[20] Karaboga, D., 2005, An idea based on honey bee swarm for numerical optimization (Vol. 200, pp. 1-10), Technical Report TR06, Department of Computer Engineering, Engineering Faculty, Erciyes University, Turkey.

[21] Karaboga, D., Basturk, B., 2007, Artificial Bee Colony (ABC) Optimization Algorithm for Solving Constrained Optimization Problems,
International Fuzzy Systems Association World Congress, Cancun-Mexico June 2007, Springer, Berlin, Heidelberg, pp. 789-798.

[22] Karaboga, D., Basturk, B., 2008, On the performance of artificial bee colony (ABC) algorithm, Applied Soft Computing, 8(1), 687697.

[23] Singh, A., 2009, An artificial bee colony algorithm for the leaf-constrained minimum spanning tree problem, Applied Soft Computing, 9(2), 625-631

[24] Yang, X.S., 2011, Bat algorithm for multiobjective optimization, International Journal of Bio-Inspired Computation, 3(5), 267-274.

[25] Yang, X.S., Karamanoglu, M., Fong, S., 2012, Bat algorithm for topology optimization in microelectronic applications, The First International Conference on Future Generation Communication Technologies, 12-14 December 2012 London-UK, IEEE, pp. 150155.

[26] Yang, X.S., Karamanoglu, M. (2013). 'Swarm Intelligence and Bio-inspired Computation: An Overview' in Xin-She Yang, Zhihua Cui, Renbin Xiao, Amir Hossein Gandomi, Mehmet Karamanoglu (eds.) Swarm Intelligence and Bio-inspired Computation. Elsevier, pp. 3-23.

[27] Hasançebi, O., Teke, T., Pekcan, O., 2013, A bat-inspired algorithm for structural optimization, Computers \& Structures, 128, 779

[28] Fleury, C., Braibant, V., 1986, Structural optimization: a new dual method using mixed variables, International Journal for Numerical Methods in Engineering, 23, 409-428.

[29] Svanberg, K., 1987, The method of moving asymptotes - a new method for structural optimization, International Journal for Numerical Methods in Engineering, 24(2), 359373.

[30] Chickermane, H., Gea, H.C., 1996, Structural optimization using a new local approximation method, International Journal for Numerical Methods in Engineering, 39(5), 829-846.

[31] Gandomi, A.H., Yang, X.S., Alavi, A.H., 2013, Cuckoo search algorithm: a metaheuristic approach to solve structural optimization problems, Engineering with Computers, 29(1), 17-35.

[32] Toropov, V.V., Filatov, A.A., Polynkin, A.A., 1993, Multiparameter structural optimization using FEM and multipoint explicit approximations, Structural Optimization, 6(1), 7-14. 
[33] Polynkin, A., Toropov, V., Shahpar, S., 2008, Adaptive and Parallel Capabilities in the Multipoint Approximation Method, 12th AIAA/ISSMO Multidisciplinary Analysis and Optimization Conference, 10-12 September 2008 Victoria, British Columbia-Canada, pp. 5803.

[34] Chou, J.S., Ngo, N.T., 2017, Modified firefly algorithm for multidimensional optimization in structural design problems, Structural and Multidisciplinary Optimization, 55(6), 20132028.

[35] Shabani, A., Asgarian, B., Gharebaghi, S.A., Salido, M.A., Giret, A., 2019, A new optimization algorithm based on search and rescue operations, Mathematical Problems in Engineering, 2019. 